www.jmscr.igmpublication.org

Impact Factor 5.84

Index Copernicus Value: 71.58

ISSN (e)-2347-176x ISSN (p) 2455-0450

crossref DOI:_https://dx.doi.org/10.18535/jmscr/v5i11.154

Journal Of Medical Science And Clinical Research

\title{
Correlation of Severity of Dengue Fever with Serum Transaminase Levels: A Retrospective Study
}

\begin{abstract}
Authors
Abhishek Kumar Verma ${ }^{1}$, Prabhakar K. ${ }^{2}$, Reddy Prasad ${ }^{3}$

${ }^{1}$ Post Graduate Student, Dept of General Medicine, Sri Devaraj URS Medical College, Kolar, Karnataka

${ }^{2}$ Professor, Department of General Medicine, Sri Devaraj URS Medical College, Kolar, Karnataka

${ }^{3}$ Assistant Professor, Department of General Medicine, Sri Devaraj URS Medical College, Kolar, Karnataka

Abstract

Dengue infection is a major health problem worldwide including our country. Dengue, one of the most rapidly spreading mosquito-borne viral diseases in the world, is an acute infection caused by an arbovirus in the Flavivirus genus, and the mosquito Aedes aegypti is the vector. Epidemic dengue is a major public health problem in South East Asia, especially in India where there is a reported case fatality ratio of $3-$ $5 \%$. One of the most prominent clinical characteristics of dengue patients is increased aspartate and alanine aminotransferase liver enzyme levels. The significance of this is uncertain, as it is transient in the majority of cases, and most patients recover uneventfully without liver damage.

Methods and Material: This study included 42 patients of dengue positive cases admitted in RL Jalappa hospital, Tamaka Kolar, Karnataka. We included all patients diagnosed dengue positive in this study. Excluded based on exclusion criteria.

Results: Among 42 patients enrolled, males comprised $71 \%$ (30), females 29\% (22) of the study population and median age of study population was 32 years (25-45 years). 21\% (9) had dengue fever without warning signs, $62 \%$ (26) had dengue with warning signs and $17 \%$ (7) had severe dengue. The main presenting symptoms were fever (100\%) followed by myalgia (54.2\%), arthralgia (53\%), hemorrhagic manifestations (46.4\%), vomiting (40.4\%) and abdominal pain (27.1\%). Hepatomegaly was observed in $11.4 \%$ patients in this study. Among 42 patients $90.4 \%$ (38) patients were positive for NS1Ag, IgM 71.4\% (30), $33.3 \%$ (14) and IgG and NSIAg 59.52\% (25). In our study 12 patients had normal level of serum transaminases (grade A, 28.5\%), 30 (71.4\%) had elevated enzymes in which 17 falling into the grade B (40.4\%), 10 in grade C (23.3\%) and 3 in the group D (7.1\%). Among 30 patients with raised serum transaminases all had elevated AST whereas only 24 (80\%) had elevated ALT. Mean AST value was $396 \pm 746 \mathrm{IU} / \mathrm{L}$ and mean ALT was $285 \pm 460 \mathrm{IU} / \mathrm{L}$. The characteristics of ALT and AST among study population is as shown below in the table.

Conclusion: In conclusion, all serologically confirmed dengue infection patients, liver involvement in the form of elevation of transaminases levels occurred in almost all patients. However, association with the severity of the disease could not be sought due to the small sample size. Most of our patient developed jaundice and acute hepatitis but most patient had mild to moderate effect and recovered with supportive treatment. Care must be taken not to make a mistaken diagnosis of viral hepatitis.
\end{abstract}




\section{Introduction}

Dengue is the most common mosquito-borne viral disease and is caused by an Arbovirus belonging to Flavivirus genus, and vector is mosquito Aedes aegypti. Each year more than 390 million cases occur all over the world. ${ }^{1}$ Dengue epidemic is a major public health problem in South East Asia, especially in India where there is a reported case fatality ratio of $3-5 \% .^{2}$ It has various clinical presentations which may range from mild febrile illness to life threatening shock syndrome as well as unusual manifestations such as hepatitis, encephalitis, myocarditis, Reye's syndrome, hemolytic uremic syndrome and thrombocytopenic purpura. ${ }^{3}$ Dengue virus is a non hepatotropic virus but liver injury due to dengue infection is not uncommon and has been described since the 1960s. ${ }^{4}$ Hepatic involvement can lead to acute hepatitis and characterized by pain in the right hypochondrium, hepatomegaly, jaundice, and raised aminotransferase levels. In hepatitis, the levels of these enzymes reach a maximum on the ninth day after the onset of symptoms, and they gradually return to normal levels within three weeks. Histopathological findings of liver involvement include centrilobular necrosis, fatty alteration, hyperplasia of Kupffer cells, acidophil bodies, and monocyte infiltration of portal tract. ${ }^{5}$

Our study was done to evaluate the frequency of liver involvement and aminotransferase level change in dengue fever and to determine relation of transaminase level change with the disease severity.

\section{Materials and Methods}

A total of 42 patients, attended, RLJH attached to SDUAHER, Tamaka, Kolar, between August and September 2015 were included in the study.

\section{Inclusion Criteria}

- All patients with age more than 18years and Dengue NS1Ag/IgG/IgM positive status.

\section{Exclusion Criteria}

Patients with

- Malaria
- Typhoid

- Leptospirosis

- History of alcohol abuse

- Chronic liver disease

- Viral hepatitis (Hepatitis A, Hepatitis B, Hepatitis C)

All patients were evaluated with detailed history including age, sex, presenting symptoms; history of co morbid illness; alcohol consumption and use of hepatotoxic drugs were noted.

Dengue was suspected when two or more of the following symptoms were present: fever, retroorbital pain, myalgia, arthralgia, skin rash, nausea/vomiting, and hemorrhagic manifestations. Complete blood counts and liver function tests were done. Antidengue antibodies and/or NS1 antigen test were carried out in all patients. These samples were subjected to immunoenzymatic assay (Panbio dengue IgM Capture ELISA). When results of either of these two tests were positive, patients were considered to be currently infected with dengue virus, while cases in which the results were negative were considered unconfirmed.

The involvement of liver was classified into four groups based on aspartate aminotransferase (AST) and alanine aminotransferase (ALT) levels. The reference value of AST and ALT was 40 U/l. Patients with normal aminotransferase levels were assigned Grade A. Those with the level of at least one of the aminotransferases elevated but less than 3 times the reference range were assigned Grade B. Patients with the level of at least one of the aminotransferases more than 3 times the reference range but less than 10 times the reference value were graded as $\mathrm{C}$, and those with an increase in the level of one or both the enzymes more than 10 times were classified as Grade D, thereby defining the presence of hepatitis. In these patients, other causes of hepatitis were ruled out using appropriate test.

\section{Results}

Among 42 patients enrolled, males comprised $71 \%$ (30), females $29 \%$ (22) of the study 
population and median age of study population was 32 years (25-45 years). $21 \%$ (9) had dengue fever without warning signs, $62 \%$ (26) had dengue with warning signs and $17 \%$ (7) had severe dengue.

The main presenting symptoms were fever which was present in all patients (100\%), headache in patients $(80.7 \%)$, myalgia in patients $(54.2 \%)$, arthralgia in patients (53\%), hemorrhagic manifestations in patients $(46.4 \%)$, vomiting in patients $(40.4 \%)$ and abdominal pain in patients (27.1\%). Hepatomegaly was observed in $11.4 \%$ patients in this study. Among 42 patients $90.4 \%$ (38) patients were positive for NS1Ag, IgM $71.4 \%(30), 33.3 \%$ (14) and $\mathrm{IgG}$ and $\mathrm{NS} 1 \mathrm{Ag}$ $59.52 \%(25)$.

In our study 12 patients had normal level of serum transaminases (grade A, 28.5\%), 30 (71.4\%) had elevated enzymes in which 17 falling into the grade B $(40.4 \%), 10$ in grade C $(23.3 \%)$ and 3 in the group D $(7.1 \%)$. Among 30 patients with raised serum transaminases all had elevated AST whereas only 24 (80\%) had elevated ALT. Mean AST value was $396 \pm 746 \mathrm{IU} / \mathrm{L}$ and mean ALT was $285 \pm 460 \mathrm{IU} / \mathrm{L}$. The characteristics of ALT and AST among study population is as shown below in the table.

The correlation between serum transaminase level in the severity of dengue is depicted in the below table.

Table 1.

\begin{tabular}{|l|c|c|}
\hline Parameters & $\begin{array}{c}\text { Subjects With Positive } \\
\text { Serological Tests For } \\
\text { Dengue }\end{array}$ & P Value \\
\hline Age (Years) & $35( \pm 10)$ & 0.356 \\
Platelets (Cells/Mm3) & $66,866( \pm 10256)$ & $<0.0002$ \\
Total Bilirubin (Mg/Dl) & $1.3( \pm 1.4)$ & 0.22 \\
Direct Bilirubin (Mg/Dl) & $0.62( \pm 1.06)$ & 0.26 \\
Total Protein (G/Dl) & $6.75( \pm 0.54)$ & 0.0012 \\
Albumin (G/Dl) & $3.86( \pm 0.33)$ & 0.0345 \\
Globulin (G/Dl) & $2.40( \pm 0.26)$ & 0.0236 \\
Ast (U/L) & $396( \pm 746)$ & 0.032 \\
Alt (U/L) & $285( \pm 460)$ & 0.021 \\
Alp[ (U/L) & $94.47( \pm 60.2)$ & 0.75 \\
\hline
\end{tabular}

Table 2

\begin{tabular}{|l|c|c|c|c|c|}
\hline Classification & Mean & $\mathrm{A}(\%)$ & $\mathrm{B}(\%)$ & $\mathrm{C}(\%)$ & $\mathrm{D}(\%)$ \\
\hline Male & 30 & 9 & 13 & 7 & 2 \\
\hline Female & 12 & 3 & 5 & 3 & 1 \\
\hline AST & $396( \pm 746)$ & 3 & 15 & 18 & 6 \\
\hline ALT & $285( \pm 460)$ & 7 & 23 & 7 & 4 \\
\hline
\end{tabular}

\section{Table 3}

\begin{tabular}{|l|c|c|c|}
\hline $\begin{array}{l}\text { Dengue Without } \\
\text { Warning Sign }\end{array}$ & $\begin{array}{l}\text { Dengue With } \\
\text { Warning Sign }\end{array}$ & Severe Dengue & Total \\
\hline 9 & 26 & 7 & 42 \\
\hline
\end{tabular}

\section{Table 4}

\begin{tabular}{|l|l|}
\hline Dengue Without Warning Sign (9) & Grade $A=7$ \\
\cline { 2 - 2 } & Grade $B=2$ \\
\cline { 2 - 2 } & Grade $C=0$ \\
\cline { 2 - 2 } & Grade $\mathrm{D}=0$ \\
\hline Dengue With Warning Sign (26) & Grade $\mathrm{A}=0$ \\
\cline { 2 - 2 } & Grade $\mathrm{B}=15$ \\
\cline { 2 - 2 } & Grade $\mathrm{C}=6$ \\
\cline { 2 - 2 } & Grade $\mathrm{D}=0$ \\
\hline Severe Dengue (7) & Grade $\mathrm{A}=0$ \\
\hline & Grade $\mathrm{B}=0$ \\
\cline { 2 - 2 } & Grade $\mathrm{C}=4$ \\
\cline { 2 - 2 } & Grade $\mathrm{D}=3$ \\
\hline
\end{tabular}

\section{Discussion}

Hepatic involvement in dengue is manifested by hepatomegaly clinically or increase in liver enzymes biochemically. ${ }^{6}$ In our study special attention was put on change in the serum transaminase levels among dengue patients. Hepatomegaly was observed in $11.4 \%$ patients in this study compared to $12.1 \%$ in Rajoo et al and $17.6 \%-20.4 \%$ in other Indian studies. There was presence of hepatic dysfunction in most of our patients as evidenced by increased level of serum transaminases in $30(71.4 \%)$ patients.

In this study patients who has grade $\mathrm{B}, \mathrm{C}$, or D hepatic involvement, elevation of AST occurred in most cases $(71.4 \%)$ either together with elevation of ALT or as alone. ALT levels were normal in $41.4 \%$ of the patients compared to normal AST levels in $28.5 \%$ patients.

Similar results were found in the study conducted by Srivenu Itha et al where $97 \%$ had hepatic involvement with raised liver enzymes. ${ }^{6}$ This general pattern with AST increasing more quickly and peaking at higher level is unusual and differs from those during acute hepatitis caused by hepatitis viruses, ${ }^{7}$ but it has been described in dengue infection. ${ }^{8}$ Given the prominence of musculoskeletal symptoms in dengue, skeletal 
muscle injury could explain the higher AST levels.

Louiz $\mathbf{J}$ de $\mathrm{S}$ et al had studied aminotransferase changes and acute hepatitis in 1,585 dengue patients. ${ }^{9}$ Their average AST level was greater than that of ALT in both DF and DHF. They also found higher average AST and ALT value in DHF than DF which is similar to our findings. De Souza et al. classified $42.5 \%$ of patients as Grade B, $17.5 \%$ as Grade C, and only $1.8 \%$ as Grade D, according to aminotransferases' levels. ${ }^{10}$ Almost all the patients with deranged hepatic enzymes during the period of our study returned to normal within 2- 3 weeks. The above findings were also almost similar with the findings of Kuo et al. where 270 dengue patients were evaluated and had raised AST and ALT in $93.2 \%$ and $82.2 \%$ cases respectively with greater elevation of AST than ALT which returned to normal after 3 weeks. Kuo et al. also reported that most severely ill patients had higher levels of aminotransferases and lower level of globulin, whereas increases in albumin, alkaline phosphatase (ALP), bilirubin, and prothrombin were not related to the severity of the disease. ${ }^{11}$ Similarly, in the our study, globulin levels were significantly lower in confirmed cases. The reduction in serum globulin is an important factor in fluid loss in the third space, which is indicative of severity of dengue due to reduction in gradient of intra and extravascular pressure. Thus, AST, ALT, and globulin are valuable parameters for evaluation of severity of infection. ${ }^{12}$

our study has some limitations as small sample size so exact association of aminotransferases with different grades of dengue fever could not be ascertained.

A large and multicentric study is needed to truly establish whether the aminotransferases could be used as a prognostic marker.

\section{Conclusion}

In conclusion, all serologically confirmed dengue infection patients, liver involvement in the form of elevation of transaminases levels occurred in almost all patients. However, association with the severity of the disease could not be sought due to the small sample size. Most of our patient developed jaundice and acute hepatitis but most patient had mild to moderate effect and recovered with supportive treatment. Care must be taken not to make a mistaken diagnosis of viral hepatitis.

\section{References}

1. Bhatt S, Gething PW, Brady OJ, Messina JP, Farlow AW, Moyes CL et al. The global distribution and burden ofdengue. Nature 2013; 496: 504.

2. World Health Organization. Dengue guidelines for diagnosis, treatment, prevention and control. New Edition. Geneva: World HealthOrganization Publishers; 2009. p. 46.

3. Marianneau O, Flamand M, Deubel V. Apoptotic cell deathin response to dengue virus infection: the pathogenesis ofdengue hemorrhagic fever revisited. Clin Diagn Virol 1998;10: 113-19.

4. Gubler DJ. Dengue and dengue hemorrhagic fever: its history and resurgence as a global public health problem. In: Gubler DJ, Kuno G, ed. Dengue and Dengue Hemorrhagic Fever, Willingford: CAB International; 1997:1-22.

5. Jnaneshwari M, Jayakumar S, Arun Kumar, Uday G. "Study of serum aminotransferase levels in dengue fever". Journal of Evolution of Medical and Dental Sciences 2014; Vol.3, Issue 10, March 10; Page: 2445-2455, DOI: 10.14260/jemds/2014/2157

6. Wiw ankit V. Liver dysfunction in dengue infection: An analysis of the previously published Thai cases. J Ayub Med Coll Abbottabad. 2007;19:10-2

7. Srivenu Itha, Rajesh Kashyap, Narendra Krishani, Vivek A. Saraswat, Gourdas choudhari, Rakesh Aggarwal: Profile of liver involvement in dengue virus infection Natl Med J India 2005;18:127-30. 
8. Dinh The Trung, Le Thai Thu Thao, Tran Tinh Hien, Nguyen The Hung, Nguyen Ngoc Vinh, Pham Tran Dieu Hien et al: Liver involvement associated with dengue infection in adults in Vietnam. Am. J. Trop. Med. Hyg., 83(4). 2010, pp. 774-780

9. Souza LJ, Alves JG, Nogueira RM, Gicovate Neto C, Bastos DA, Siqueira EW, Souto Filho JT, Cezario Tde A, Soares CE, Carnerio Rda C. Aminotransferase changes and acute hepatitis in patient with dengue fever: analysis of 1,585 cases. Braz J Infect Dis. 2004;8:156-163

10. Luiz Jose de Souza, Jose Galvao Alves, Rita Maria Ribeiro Nogueira, Carlos Gicovate Neto, Diogo Assed Bastos, Edno Wallace da Silva Siqueira et al: Aminotransferase changes and acute hepatitis in patient with dengue fever: analysis of 1,585 cases. Braz $\mathrm{J}$ infect Dis Vol.8 no. 2 Salvador Apr.2004

11. Kuo CH, Thai DI, Chang-Chien CS, Lan CK, Chiou SS, Liaw YF. Liver biochemical tests and dengue fever. Am J Trop Med Hyg 1992;47:265-70

12. De Souza LJ, Nogueira RM, Soares CE, Ribas BF, Alves FP ET AL. The impact of dengue on liver function as evaluated by aminotransferase levels. Braz J Infect Dis 2007;11:407-10. 